
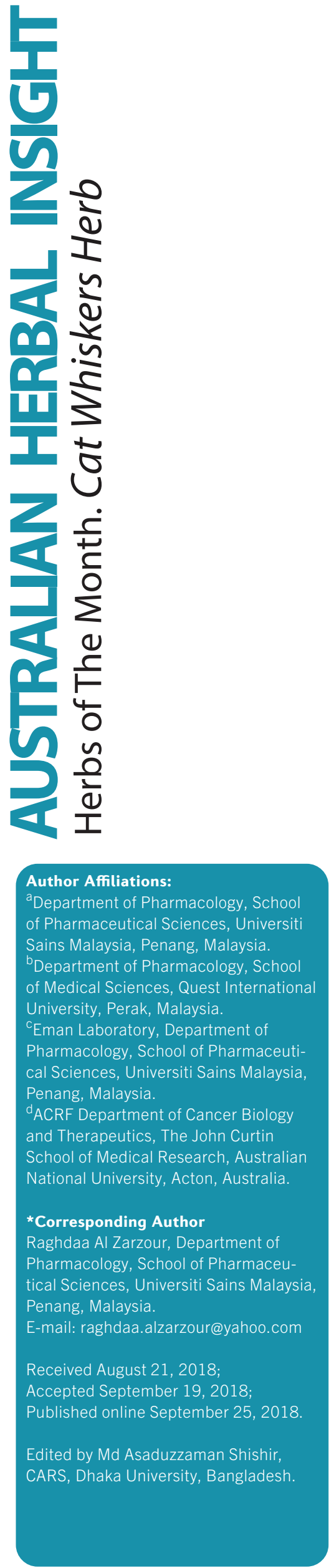

\title{
Metabolic Syndrome and Cat Whiskers Herb
}

\author{
Raghdaa Al Zarzoura*, Aman Shah Abdul Majid ${ }^{b} \&$ Amin Malik Shah \\ Abdul Majid ${ }^{c, d}$
}

\begin{abstract}
Metabolic Syndrome is a collection of associated health problems that affects much of the world population today. These include hypertension, obesity, hypercholesterolemia, and insulin resistance; all of which can increase the risk of stroke, heart disease, and type 2 diabetes. These illnesses are interrelated and having one complication can lead to several other diseases. A number of herbs that have high antioxidant and anti-inflammatory properties can help to improve the management of metabolic syndrome. Orthosiphon stamineus, also known commonly as Cat Whiskers herb is widely used in the Asian region to treat metabolic syndrome associated health problems. This is due to its unique phytochemical properties that target key biochemical pathways that are involved in metabolic diseases. This review highlights key aspects of Metabolic Syndrome and how Cat Whiskers herb can play an important role in treating this disease.
\end{abstract}

Key words: Metabolic Syndrome, diabetes, hypertension, Orthosiphon stamineus, Cat Whiskers.

\section{Introduction}

Historically as early as in the 1920 s, the inter-relationship between diabetes, hypertension and gout have been proposed by many scientific studies. Much later in 1947, demonstrated that there is a causative relationship between obesity and a cluster of pathological conditions such as cardiovascular disease, type 2 diabetes mellitus (T2DM), hypertension, and dyslipidemia. Back in 1988 this group of diseases was then named "syndrome X", and in 1992 it was redefined as "the insulin resistance syndrome". Finally, in 2001, the term of "Metabolic Syndrome" was coined and became known to the general public for the first time (Eckel et al., 2005).

Metabolic syndrome can be defined as a pathophysiological state that links a collection of metabolic disorders i.e. hyperglycaemia, hyperlipidaemia, hyperuraecemia etc., that can occur together or one predisposing to the other. Sufferers tend to have higher risk of developing type 2 diabetes, cardiovascular and cerebrovascular disease such as angina, cardiac failure and stroke which then can lead to related end organ complications such as kidney, lungs, liver and brain disorders (Johnson et al., 2007). The main causes of metabolic syndrome are not clearly understood but a genetic link is probable. Being overweight and physically inactive increase one's risk of developing metabolic syndrome (Misra and Khurana, 2008).

Metabolic syndrome was found to be typically predominant among obese individuals who consume high quantity of fast food and live a sedentary inactive life style (Kelishadi et al., 2008). It is now well established that various human subgroups who are at risk can be vulnerable to developing metabolic syndrome. This can develop both in obese and lean individuals, males and females, adults and children, which suggests that the problem of obesity is just an 'eye-wash' to explain the causative factor of this syndrome and is not the direct cause. However, what seems clear is that insulin resistance is a fundamental underlying pathophysiologic process and can be said to be the corner stone in understanding this syndrome. Moreover, it is has been 


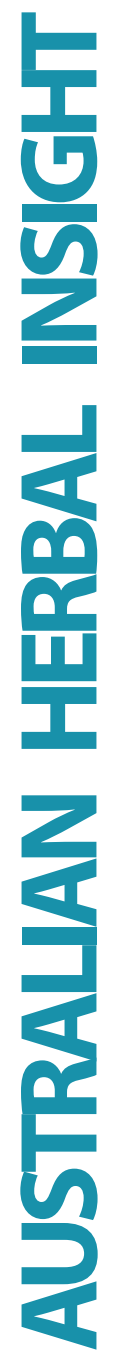

well described and suggested recently that insulin resistance in adipose tissue is linked to the development of obesity in the pathogenesis of the metabolic syndrome (Weiss et al., 2013).

Early symptoms of metabolic syndrome may include the elevation of blood uric acid (Ishizaka et al., 2005). This may lead to symptoms of gout and even kidney stones (Jeong et al., 2011). Interestingly gout which is a form of arthritis has also been linked to the metabolic syndrome phenomena (Hench, 1936), as sufferers of gout have been found to have higher risk of developing type 2 diabetes (Choi et al., 2008). The presence of high uric acid in the blood will also predispose to chronic kidney damage caused by uric acid crystals present in the kidney. As the kidney functions starts to deteriorate

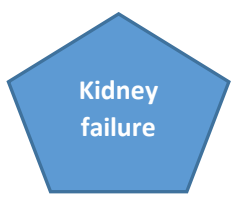

Diabetic

blindness

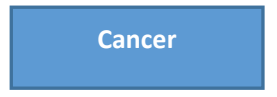

blood pressure will also tend to increase. Hence suffering from gout can predispose patients to a range of early and late clinical complications.

The main late clinical features and complications observable in metabolic syndrome patients are visceral obesity, dyslipidemia, hypertension, atherosclerosis, T2DM, Non-alcoholic fatty liver disease (NAFLD) (Liver and Diabetes, 2016), Polycystic ovarian syndrome (PCOS) (Ranasinha et al., 2015), obstructive sleep apnea, pro-inflammatory state and oxidative stress (Benedict and Zhang, 2017). theClinical blood biochemistry will also show the abnormalities in serum alanine aminotransferase (ALT), aspartate aminotransferase (AST) levels (Sattar et al., 2004), especially when there is a family history of T2DM (Ballestri et al.,
2016), signs of insulin resistance such as acanthosis Nigricans, maternal history of diabetes and so on (Love-Osborne et al., 2008) (Fagot-Campagna et al., 2000).

In metabolic syndrome sufferers, fat accumulation around the liver commonly referred as fatty liver, occurs mainly due to the inability of the liver to sufficiently metabolise the excess carbohydrate from the food intake (Lonardo et al., 2015). The excess fat surrounding the liver makes the body less responsive to the body's own insulin (Gaggini et al., 2013). This causes elevated blood sugar level and increases the harmful LDL cholesterol. The body will try to eliminate the excess sugar through the kidneys which makes the "sugary" urine a fertile ground for bacterial growth causing urinary tract infection (UTI) (Kupelian et al., 2009) . High blood 


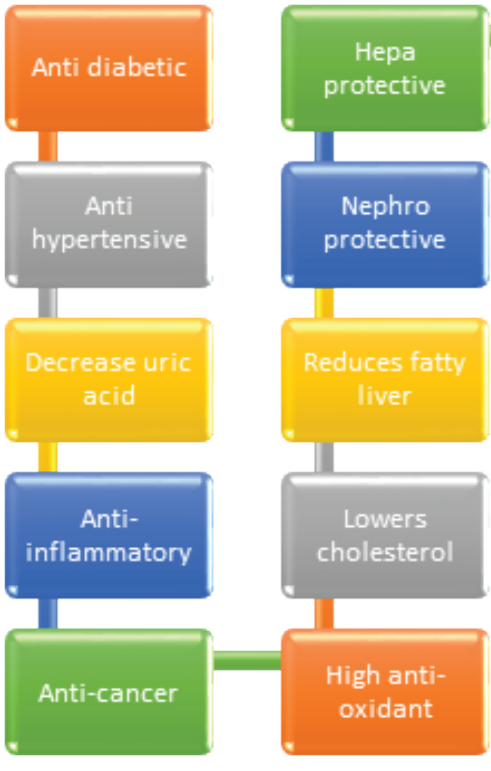

damage to the blood vessels causing plaque formation in the arteries which can cause blockages leading to heart attack and stroke. High blood sugar and blood pressure will cause damage to the blood vessels leading to plaque formation in the arteries which can cause blockages leading to a heart attack and stroke. High blood sugar and elevated blood pressure can also cause free radical damage and inflammation to vital organs and tissues such as the kidneys, eyes, brain and heart (McFarlane and Sowers, 2003). Neurological conditions such as Alzheimer's disease (Raffaitin et al., 2008), Multiple Sclerosis (Wens et al., 2013) and diabetic neuropathy (Pittenger et al., 2005) are some of the potential diseases that are linked to these events. The prolonged state of inflammation can also potentially cause disease such as cancer. In addition women who suffers from metabolic syndrome are also at risk of developing Polycystic Ovarian Syndrome (PCOS) where the main clinical features include menstrual irregularities, sub-fertility, hyperandrogenism, and hirsutism (Ehrmann et al., 2006). PCOS have similar features of metabolic syndrome such

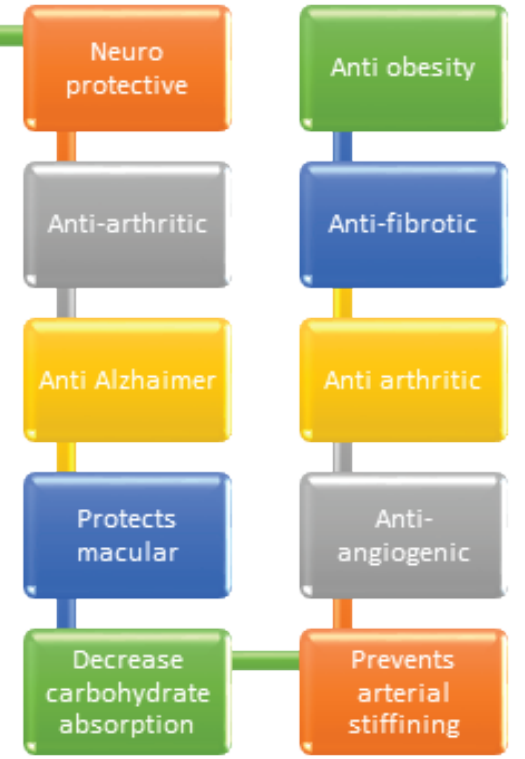

as insulin resistance and visceral obesity. These place women with metabolic syndrome at higher risk of developing cardiovascular disease (CVD), Type 2 diabetes (DMT2) and gynaecological cancer.

Metabolic syndrome suffers tend to have elevated level of free radicals in their blood plasma which in turn causes inflammation throughout their system. Hence it is not a surprise to find this population subgroup to have a higher risk at developing cancer (Bar-Or and Bar-Or, 2013).

\section{Metabolic Syndrome and associ- ated diseases}

It has been suggested that aerobic exercise, healthy lifestyle intervention and caloric restriction can effectively prevent and control metabolic syndrome due to the improvement in insulin sensitivity/insulin action in trained subjects. Therefore, drug therapeutic options as well as weight loss and increasing the physical activity to increase the energy expenditure have been applied to treat metabolic syndrome (Grundy et al., 2005).

Certain herbal remedies may also benefit in managing the symptoms of metabolic disorders as well as poten- tially targeting the underlying pathophysiologic imbalance of chronic inflammation and oxidative stress, through their powerful property as natural antioxidants. (Yin et al., 2008). The multitude of compounds present in herbal remedies can target a number of biochemical pathways that have been perturbed during the pathogenesis of metabolic disorder. The anti-oxidant and anti-inflammatory properties of the herbal compounds can also serve to protect vital organ and tissues from damage. Herbal based compounds can serve as a chemoprevention to protect or to delay the full onset of metabolic disease in pre-hypertensive and pre-diabetic individuals. They can also work alongside conventional therapeutics to help to better manage the disease symptoms particularly in situation when the drug treatment is not able to achieve its intended therapeutic milestone.

Cat Whiskers herb (Orthosiphon stamineus / aristatus) commonly known as Misai Kucing, Java tea, or Indian Kidney herb is a popular medicinal herb in South East Asia used to treat a wide variety of metabolic syndrome associated complications (Almatar et al., 2014).

The herb has been shown to be effective in reducing blood sugar and blood pressure (Adnyana et al., 2013). The former is by improving glucose metabolism and the latter by acting on a key enzyme called ACE which plays important role in blood pressure

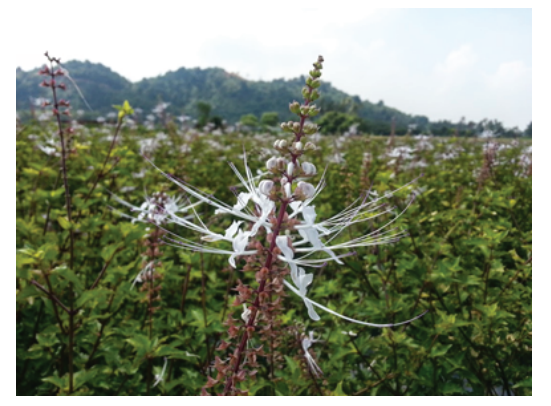


regulation. The natural diuretic property of the herb may also be responsible in reducing blood pressure by decreasing blood volume. Cat whiskers herb has also been found to be effective in reducing uric acid level, making it useful for treating symptoms of gout and rheumatic pain. This too may be attributed to its diuretic property and the analgesic property has been linked to its activity on a key enzyme that plays central role in pain and inflammation; the Cyclo-oxygenase enzyme (Cox-2) which many pain killers act upon including aspirin. The herb is also widely used to help to eliminate kidney stones and urinary tract infection (UTI) (Nguyen et al., 2004). UTI is a recognised medicinal application of Cat Whiskers herb by the European drug regulatory authorities. The activity on kidney stones is partly due to its ability to inhibit the calcium oxalate enzyme that contributes towards the formation of uric acid crystals (Ahamed et al., 2012). Scientific studies have shown that Cat Whiskers herb has powerful anti-oxidant property due to the presence of high amount of flavonoids in this herb (Abdelwahab et al., 2011). The property has been recognised as a central feature of this herb that enables it to protect the liver and the kidney from free radical damage caused by the strenuous physiological condition that occur in metabolic disease (Bala et al., 2012).

In pre-clinical laboratory studies, the herb has been shown to exert neuroprotective effects making it useful and versatile for potential use as adjunct management of certain neurological conditions. (Sree et al., 2015). One study shows that the leaf extract of Cat Whiskers herb reduced triglyceride levels and another study shows that the herb can help to significantly reduce carbohydrate and fat absorption. In addition in an in-vivo study, it was demonstrated that the Cat Whiskers can also help to reduce body weight as a consequence of administering high fat diet (Sriplang et al., 2007, Seyedan et al., 2017).

Cat whiskers herb thus has great potential in treating metabolic syndrome based on the vast scientific research supporting its traditional usage. It can especially benefit the pre-diabetic and pre-hypertensive individuals. It may also be used alongside conventional treatment for better control of blood sugar, lipids and pressure regulation in both diseased population as well as those at risk. However, no clinical data is available to support this treatment approach. Nevertheless, the possibility of Cat Whiskers herb as a complementary medicine in managing metabolic diseases complications is promising given its wide spectrum of activity towards many of the diseases that falls under the category of this disease syndrome.

\section{Acknowledgements}

The authors are thankful to NatureCeuticals to support this study.

\section{Author Contribution}

R.A.Z., A.M.S., A.S. has written and approved the paper.

\section{Competing financial interests}

The author(s) declare a competing fnancial interests. They have an interest in a herbal pharmaceutical company.

\section{References}

ABDELWAHAB, S. I., MOHAN, S., MOHAMED ELHASSAN, M., AL-MEKHLAFI, N., MARIOD, A.
A., ABDUL, A. B., ABDULLA, M. A. \& ALKHARFY, K.

M. 2011. Antiapoptotic and antioxidant properties of Orthosiphon stamineus benth (Cat's Whiskers): intervention in the $\mathrm{Bcl}$-2-mediated apoptotic pathway. Evidence-Based Complementary and Alternative Medicine, 2011.

ADNYANA, I. K., SETIAWAN, F. \& INSANU, M. 2013. From ethnopharmacology to clinical study of Orthosiphon stamineus Benth. studies, 1.

AHAMED, M. B. K., AISHA, A. F., NASSAR, Z. D., SIDDIQUI, J. M., ISMAIL, Z., OMARI, S., PARISH, C. \& MAJID, A. A. 2012. Cat's whiskers tea (Orthosiphon stamineus) extract inhibits growth of colon tumor in nude mice and angiogenesis in endothelial cells via suppressing VEGFR phosphorylation. Nutrition and Cancer, 64, 89-99.

ALMATAR, M., EKAL, H. \& RAHMAT, Z. 2014. A glance on medical applications of Orthosiphon stamineus and some of its oxidative compounds. Int J Pharm Sci Rev Res, 24, 83-88.

BALA, A., KAR, B., KARMAKAR, I., KUMAR, R. S. \& HALDAR, P. K. 2012. Antioxidant activity of Cat's whiskers flavonoid on some reactive oxygen and nitrogen species generating inflammatory cells is mediated by scavenging of free radicals. Chinese journal of natural medicines, 10, 321-327.

BALLESTRI, S., ZONA, S., TARGHER, G., ROMAGNOLI, D., BALDELLI, E., NASCIMBENI, F., ROVERATO, A., GUARALDI, G. \& LONARDO, A. 2016. Nonalcoholic fatty liver disease is associated with an almost twofold increased risk of incident type 2 diabetes and metabolic syndrome. Evidence from a systematic review and meta-analysis. Journal of gastroenterology and hepatology, 31, 936-944. BAR-OR, D. \& BAR-OR, R. 2013. Measurement and uses of oxidative status. Google Patents. BENEDICT, M. \& ZHANG, X. 2017. Non-alcoholic fatty liver disease: An expanded review. World journal of hepatology, 9, 715.

CHOI, H., DE VERA, M. \& KRISHNAN, E. 2008. Gout and the risk of type 2 diabetes among men with a high cardiovascular risk profile. Rheumatology, 47, 1567-1570.

ECKEL, R. H., GRUNDY, S. M. \& ZIMMET, P. Z. 2005 The metabolic syndrome. The lancet, 365 , $1415-1428$

EHRMANN, D. A., LILJENQUIST, D. R., KASZA, K., AZZIZ, R., LEGRO, R. S., GHAZZI, M. N. \& GROUP, P. T. S. 2006. Prevalence and predictors of the 
ovary syndrome. The Journal of Clinical Endocri-

nology \& Metabolism, 91, 48-53.

FAGOT-CAMPAGNA, A., PETTITT, D. J., ENGELGAU, M. M., BURROWS, N. R., GEISS, L. S., VALDEZ, R., BECKLES, G. L., SAADDINE, J., GREGG, E. W. \& WILLIAMSON, D. F. 2000. Type 2 diabetes among North adolescents: An epidemiologic health perspective. The Journal of pediatrics, 136, 664-672.

GAGGINI, M., MORELLI, M., BUZZIGOLI, E., DEFRONZO, R. A., BUGIANESI, E. \& GASTALDELLI, A. 2013. Non-alcoholic fatty liver disease (NAFLD) and its connection with insulin resistance, dyslipidemia, atherosclerosis and coronary heart disease. Nutrients, 5, 1544-1560. GRUNDY, S. M., CLEEMAN, J. I., DANIELS, S. R., DONATO, K. A., ECKEL, R. H., FRANKLIN, B. A., GORDON, D. J., KRAUSS, R. M., SAVAGE, P. J. \& SMITH JR, S. C. 2005. Diagnosis and management of the metabolic syndrome: an American Heart Association/National Heart, Lung, and Blood Institute scientific statement. Circulation, 112, 2735-2752.

HENCH, P. S. 1936. The diagnosis of gout and gouty arthritis. The Journal of Laboratory and Clinical Medicine, 22, 48-55.

ISHIZAKA, N., ISHIZAKA, Y., TODA, E.-I., NAGAI, R. \& YAMAKADO, M. 2005. Association between serum uric acid, metabolic syndrome, and carotid atherosclerosis in Japanese individuals. Arteriosclerosis Thrombosis and Vascular Biology, 25, 1038-1044.

JEONG, I. G., KANG, T., BANG, J. K., PARK, J., KIM, W., HWANG, S. S., KIM, H. K. \& PARK, H. K. 2011. Association between metabolic syndrome and the presence of kidney stones in a screened population. American Journal of Kidney Diseases, 58, 383-388.

JOHNSON, R. J., SEGAL, M. S., SAUTIN, Y., NAKAGAWA, T., FEIG, D. I., KANG, D.-H., GERSCH, M. S., BENNER, S. \& SÁNCHEZ-LOZADA, L. G. 2007. Potential role of sugar (fructose) in the epidemic of hypertension, obesity and the metabolic syndrome, diabetes, kidney disease, and cardiovascular disease-. The American journal of clinical nutrition, 86, 899-906.

KELISHADI, R., ALIKHANI, S., DELAVARI, A., ALAEDINI, F., SAFAIE, A. \& HOJATZADEH, E. 2008. Obesity and associated lifestyle behaviours in Iran: findings from the first national non-communicable disease risk factor surveillance survey. Public health nutrition, 11, 246-251. KUPELIAN, V., MCVARY, K. T., KAPLAN, S. A., HALL, S. A., LINK, C. L., AIYER, L. P., MOLLON, P., TAMIMI, N., ROSEN, R. C. \& MCKINLAY, J. B. 2009. Association of lower urinary tract symptoms and the metabolic syndrome: results from the Boston Area Community Health Survey. The Journal of urology, 182, 616-625. 2016. EASL-EASD-EASO Clinical Practice Guidelines for the management of non-alcoholic fatty liver disease. Obesity facts, 9, 65-90.

LONARDO, A., BALLESTRI, S., MARCHESINI, G., ANGULO, P. \& LORIA, P. 2015. Nonalcoholic fatty liver disease: a precursor of the metabolic syndrome. Digestive and Liver Disease, 47, 181-190.

LOVE-OSBORNE, K. A., NADEAU, K. J., SHEEDER, J., FENTON, L. Z. \& ZEITLER, P. 2008. Presence of the metabolic syndrome in obese adolescents predicts impaired glucose tolerance and nonalcoholic fatty liver disease. Journal of Adolescent Health, 42, 543-548.

MCFARLANE, S. I. \& SOWERS, J. R. 2003. Aldosterone function in diabetes mellitus: effects on cardiovascular and renal disease. The Journal of Clinical Endocrinology \& Metabolism, 88, 516-523.

MISRA, A. \& KHURANA, L. 2008. Obesity and the metabolic syndrome in developing countries. The Journal of Clinical Endocrinology \& Metabolism, 93, s9-s30.

NGUYEN, M. T. T., AWALE, S., TEZUKA, Y., LE TRAN, Q., WATANABE, H. \& KADOTA, S. 2004. Xanthine oxidase inhibitory activity of Vietnamese medicinal plants. Biological and Pharmaceutical Bulletin, 27, 1414-1421.

PITTENGER, G. L., MEHRABYAN, A., SIMMONS, K., DUBLIN, C., BARLOW, P. \& VINIK, A. I. 2005. Small fiber neuropathy is associated with the metabolic syndrome. Metabolic Syndrome and Related Disorders, 3, 113-121.

RAFFAITIN, C., GIN, H., EMPANA, J.-P. HELMER, C., BERR, C., TZOURIO, C., PORTET, F., DARTIGUES, J.-F., ALPÉROVITCH, A. \& BARBERGER-GATEAU, P. 2008. METABOLIC SYNDROME AND RISK FOR INCIDENT ALZHEIMER'S DISEASE OR VASCULAR DEMENTIA: THE
THREE-CITY STUDY. Diabetes care.

RANASINHA, S., JOHAM, A., NORMAN, R., SHAW, J., ZOUNGAS, S., BOYLE, J., MORAN, L. \& TEEDE, H. 2015. The association between Polycystic Ovary Syndrome (PCOS) and metabolic syndrome: a statistical modelling approach. Clinical endocrinology, 83, 879-887.

SATTAR, N., SCHERBAKOVA, O., FORD, I., O'REILLY, D. S. J., STANLEY, A., FORREST, E., MACFARLANE, P. W., PACKARD, C. J., COBBE, S. M. \& SHEPHERD, J. 2004. Elevated alanine aminotransferase predicts new-onset type 2 diabetes independently of classical risk factors, metabolic syndrome, and C-reactive protein in the west of Scotland coronary prevention study. Diabetes, 53, 2855-2860.

SEYEDAN, A., ALSHAWSH, M. A., ALSHAGGA, M. A. \& MOHAMED, Z. 2017. Antiobesity and lipid lowering effects of Orthosiphon stamineus in high-fat diet-induced obese mice. Planta medica, 83, 684-692.

SREE, N. V., SRI, P. U. \& RAMARAO, N. 2015 Neuro-protective properties of orthosiphon staminus (benth) leaf methanolic fraction through antioxidant mechanisms on sh-sy5y cells: an in-vitro evaluation. INTERNATIONAL JOURNAL OF PHARMACEUTICAL SCIENCES AND RESEARCH, 6 , 1115-1125.

SRIPLANG, K., ADISAKWATTANA, S., RUNGSIPIPAT, A. \& YIBCHOK-ANUN, S. 2007. Effects of Orthosiphon stamineus aqueous extract on plasma glucose concentration and lipid profile in normal and streptozotocin-induced diabetic rats. Journal of Ethnopharmacology, 109, 510-514.

WEISS, R., BREMER, A. A. \& LUSTIG, R. H. 2013. What is metabolic syndrome, and why are children getting it? Annals of the New York Academy of Sciences, 1281, 123-140.

WENS, I., DALGAS, U., STENAGER, E. \& EIJNDE, B. O. 2013. Risk factors related to cardiovascular diseases and the metabolic syndrome in multiple sclerosis-a systematic review. Multiple Sclerosis Journal, 19, 1556-1564.

YIN, J., ZHANG, H. \& YE, J. 2008. Traditional Chinese medicine in treatment of metabolic syndrome. Endocrine, Metabolic \& Immune Disorders-Drug Targets (Formerly Current Drug Targets-Immune, Endocrine \& Metabolic Disorders), 8, 99-111. 